\title{
The Influence of Loving-Kindness Meditation on Mental Health—A Systematic Review
}

\author{
Zichun Zhao*
}

\author{
University Malaya, Kuala Lumpur, Malaysia \\ *Corresponding author. Email: s2030299@siswa.um.edu.my
}

\begin{abstract}
Loving-Kindness Meditation is a psychological training method used to develop love and release negative emotions. Loving-Kindness Meditation originates from the tradition of Buddhist meditation. Buddhism is fundamentally related to psychology. Therefore, with the attention of psychologists to Buddhist meditation, "mindfulness" in Buddhist meditation has been widely popular in psychological research. As another important meditation technique in Buddhist meditation. Loving-Kindness Meditation is the most distinctive meditation in Buddhism. It has been shown that it has the functions of promoting self-harmony, enhancing self-acceptance, and improving interpersonal relationships that are beneficial to physical and mental health. This study reviewed and sorted out the existing research on the impact of Loving Kindness Meditation on mental health, put forward suggestions for improvement in response to the existing problems in the current research, and finally summarized and looked forward to it.
\end{abstract}

Keywords: Loving-Kindness Meditation, Loving-Kindness, Mental Health, Psychotherapy

\section{INTRODUCTION}

As the "mindfulness" therapy in Buddhist meditation has become widely popular in psychological research, other techniques in Buddhism that use the mind to control emotions have attracted more and more interest from psychologists. Loving-Kindness Meditation (LKM) is a Buddhist meditation tradition with a history of more than 2500 years [1]. It is a psychological training method used to develop love and release negative emotions [2]. LKM is one of the four immeasurable meditations (FIM) in Buddhism [3]. The "Four immeasurable minds" are the cultivation of four noble attitudes to sentient beings in Buddhism, including Loving-kindness, Compassion, Appreciative Joy, and Equanimity.

Each immeasurable mind extends a way of meditation: Loving-Kindness Meditation (LKM) hopes that all beings are well; Compassion Meditation (CM) hopes that suffering people can eliminate pain and thus arouse compassion. Appreciative Joy Meditation (AJM) feels joy for all beings; Equanimity Meditation (EM) maintains an unattached and calm attitude towards any gains and losses [4]. Each type of FIM is pro-social, but they are different [5]. Loving-Kindness cultivates Compassion, Appreciative Joy, and Equanimity. They are all different aspects derived from Loving-Kindness
[2]. This means that the other three attitudes all stem from loving-kindness [6]. Therefore, LKM is considered to be the most distinctive meditation in Buddhism. It can produce more powerful benefits than several other types of meditation [7]. Both in the history of Buddhism and the past psychological research, it has been shown that it has to improve mood, promote harmony, enhance self-acceptance, improve interpersonal relationships, and other functions that are beneficial to physical and mental health [2].

Therefore, this article reviewed the research results of LKM by psychologists in recent years, discussed the utility and impact of LKM from the perspective of psychology, And combed the empirical research and clinical efficacy of LKM in mental health. Finally, it tried to propose improvement suggestions and prospects for the existing problems in the current research.

\subsection{The concept of Loving Kindness and Loving-Kindness Meditation}

The term Loving-Kindness originated in Buddhism [8]. It is translated as "Mettā" in Pali, and its meaning refers to a kind or friendly attitude. It is the state of mind of selfless and unconditional compassion for all living beings [9]. This unconditional love is not affected by any kinship or interest relationship [8]. 
Loving Kindness Meditation, Pali means "Mettā bhāvanā", is a special kind of meditation that cultivates Loving-kindness [8], which cultivates and develops unconditional kindness to all living beings [9], and that mental state of wish all beings will be well [10]. In the history of Buddhism, LKM has an important function and status [11]. According to Southern Buddhism, when a person feels upset, practicing LKM can regulate emotions [8], And with the gradual research in psychology, empirical studies have proved that LKM can enhance people's positive emotions, reduce negative emotions, cultivate a love for themselves and others, and increase happiness [4]. In other words, this kind of intervention from Buddhism can be applied to a series of psychological problems. Examples include depression, anxiety, stress, emotional depression, interpersonal skills, and fear of self-compassion [12].

\subsection{The practice method of LKM}

Compared with traditional meditation methods, the practice of LKM is simple and easy. Exercises can be carried out in lying, sitting, and walking postures. It is not restricted by space and time and can be carried out anytime and anywhere [10]. After adjusting yourself to a comfortable posture [8], start to imagine the object you want to practice LKM, and operate by repeating certain blessing language "May you be safe, may you be healthy, and may you be happy"[13]. Regarding the object of the blessing, the practitioner needs to make progress gradually. Perform multiple meditation stages, in sequence (1) bless yourself, (2) bless the loved ones, (3) neutral people (one who is emotionally neutral to them), (4) Bless people who are unacceptable and disgusted. (5) Bless all beings in the entire universe [2].

\section{THE EFFECT ON EMOTIONS}

\subsection{Increase positive emotions}

LKM is a meditation to cultivate positive emotions. At present, empirical research has verified that it increases the function of positive emotions. He et al. used a randomized controlled study in 2015 to randomly divide 50 participants who had never received any meditation training into a meditation group ( 25 people) and a control group ( 25 people) and implemented LKM intervention for the meditation group for 4 weeks, 3 times a week, about 30 minutes each time. The results show that LKM can effectively improve personal positive emotions and interpersonal communication skills [14].

Another study is a study by Sirotina et al. in 2020 that adopted a randomized controlled trial (participants did not have any meditation training experience), and only 15 minutes of LKM audio intervention was performed on the LKM group. Participants were asked to use a Self-Assessment Manikins (SAM) and Emotional Word List (EWL) to measure the influence of emotions. The results showed that the participating group of LKM increased overall positive emotions and well-being [15]. Even for a short period, LKM still effectively increases the effect of individuals in cultivating positive emotions.

\subsection{Reduce negative emotions}

As scholars deepen their research on the improvement of emotions by LKM, it has also been proven to relieve or eliminate negative emotions. Llies designed a 12-minute LKM audio exercise in 2019. Each participant was required to complete the State Mindfulness and State Anxiety Scale before and after the exercise. The results showed that after the exercise, LKM successfully reduced the initial level of anxiety of the participants [16]. In other words, even a short-term LKM can effectively reduce negative emotions such as anxiety.

Totzeck adopted a randomized controlled study in 2020 to examine whether LKM is an effective intervention to promote mental health and reduce depression, anxiety, and stress among college students. And all participants participated in the follow-up evaluation one year later. 110 college students were randomly divided into the LKM intervention group and untreated control group. The intervention group took at least 5 days a week of 15-25 minutes of group lessons, and the results showed that LKM had a significant short-term effect on anxiety. At the same time, the analysis of the long-term evaluation showed that the depression, anxiety, and stress of the LKM completers were significantly reduced, while the three indicators of the control group were significantly increased [17]. In the long term, LKM still has a significant effect on emotional state.

\section{THE EFFECT ON ATTITUDES OF SELF AND OTHERS}

LKM is an exercise to bless oneself and others and cultivate a love for oneself and others. It can reduce psychological distress, increase happiness, and improve self-compassion [13]. Weibel conducted a randomized controlled trial in 2016. For the LKM intervention group and the control group, the results reported by the participants were evaluated before treatment, after treatment, and during the 8-week follow-up. It was found that compared with the control group, the LKM intervention group had higher compassion and selfcompassion for others after treatment [18]. This shows that LKM has increased self-compassion and compassion for others [19].

LKM is a kind of cultivation of kindness to oneself and others, and it has many direct benefits to 
interpersonal communication and psychological distress [20]. Reb studied the influence of LKM in the dictator game in 2010. In the game designed by the researchers, the dictator can unilaterally decide the number of resources allocated to the opponent without being retaliated against. It was found that after a short 8minutes LKM practice before the dictator game, the LKM group provided more resources to the opponent than the control group [21].

Engle designed an experiment in 2021 to intervene entrepreneurs to face the fear of failure when facing threatening risk barriers through LKM. Results Compared with the control group, the LKM entrepreneurs who received brief guidance showed higher self-compassion in the experimental group than in the control group, which means that LKM has a significant negative impact on entrepreneurs' fear of failure through self-compassion [22]. Similarly, in a nine-month meditation training study, the LKM group increased self-acceptance and reduced self-reported stress responses [23]. Therefore, it can be proved that whether it is short-term intervention or long-term regular practice, LKM is a practical way to cultivate self-compassion and compassion for others.

\section{CLINICAL TREATMENT}

Meta-analysis shows that LKM can generally improve people's health and well-being, and more specifically, can improve the positive mood of the population [10]. And by cultivating people's selfcompassion and kindness, can enhance people's inner mental toughness, self-esteem, and social connections, and reduce the negative effects of emotions, such as the anxiety and depression mentioned above [24]. Therefore, more and more researchers try to use LKM as an auxiliary treatment method for certain diseases, to improve and enhance the quality of life of patients, and to intervene in certain problems arising from certain accompanying diseases [8].

The earliest empirical study on the application of LKM intervention in the clinic was a randomized controlled trial conducted by Carson et al. in 2005 for patients with chronic low back pain. Chronic pain is a syndrome with complex clinical mechanisms, including a combination of congenital and acquired factors it may be caused by physical diseases or mental problems. Its occurrence and development are related to psychological factors (such as anxiety and depression) are closely related [2]. The intervention lasted for 8 weeks, with a 90-minute group course once a week. The course content includes LKM exercises, knowledge explanations, and group discussions. And after class, participants need to complete 10-30 minutes of LKM practice with recording guidance. The results showed that the intervention of LKM significantly improved the pain, psychological distress, anxiety, hostility, and phobia of the intervention group [25].

Another recent study is about the psychological barrier intervention of breast cancer. Although more and more women with breast cancer receive treatment and improve survival rates, many women still experience anxiety and physical conditions such as fatigue and pain during diagnosis and surgery. Wren et al. designed a randomized controlled trial in 2019 and found that performing LKM for 20 minutes a day can effectively reduce the pain of breast cancer biopsy patients. Compared with the control group, the intervention group also showed some improvement in selfcompassion and heart rate during diagnosis and surgery [26].

In recent years, more and more studies have shown that self-criticism is also an important risk factor in some psychological problems, such as social anxiety, post-traumatic stress disorder, borderline personality disorder, self-harm, suicide, bipolar disorder, schizophrenia [2]. And LKM helps people open their hearts and experience the feelings of themselves and others in a loving, kind, peaceful, and considerate way. And produce emotions such as acceptance and caring [27]. This may help improve the patient's level of selfcompassion, reduce self-criticism, and thus have potential curative effects on the intervention and treatment of some psychological problems. Shahar et al. conducted an LKM intervention study on individuals with a high tendency to self-criticism in 2015 and conducted a follow-up study 3 months after the end of the intervention. It was found that after the intervention of LKM, participants not only reduced the level of selfcriticism but also increased the level of self-compassion, and this positive state continued after three months [28].

\section{CONCLUSION}

LKM is different from other forms of meditation. It can not only improve the individual's awareness and acceptance of the present moment but also transform the emotional state into love and goodwill for all sentient beings including oneself [29]. This leads to lasting positive emotions [15], effectively reduces negative emotions [30], and improves self-compassion [22] and altruism [21]. Pro-social emotions and behaviors generated by the enhancement of altruism and personal well-being [31], there is a positive impact on the entire society [15].

Therefore, from the perspective of mental health, the future development of LKM can try to be used in the intervention of general social psychological problems. Such as medical care, education, entrepreneurship, parent-child relationship, and other issues. The positive public health impact of LKM is not only beneficial to the individuals receiving help, but also to the helpers 
themselves [31]. The application of LKM in the cancer population can improve the physical and emotional problems of patients [30] and is considered to be a practical and promising effect. And in terms of the doctor-patient relationship, LKM helps to improve doctors' empathy and communication skills in treating patients [32].

In addition, LKM is also suitable for education to reduce the anxiety and stress of students when facing exams [33]. It can also be used to increase entrepreneurs' self-compassion, and then reduce their fear of facing threatening risk barriers (such as entrepreneurial failure) [22]. The self-compassion generated by LKM can also manage the inner tension and pain of young people when they interact with their parents in the parent-child relationship [34]. Therefore, the intervention of LKM in mental health has a positive impact on the population, It has the effect of promoting mental health for the general population and clinical patients suffering from emotional disorders in society.

At present, there are still two problems in previous researches on LKM. First, the existing literature mostly stays on the surface analysis of the effect of LKM. Few studies have deeply explored how the mechanism of LKM's psychological impact works. Some studies believe that the operating mechanism of LKM is the function of empathy [2,24], while others believe that it may be self-compassion [35]. Because LKM has the effect of enhancing self-awareness and enhancing empathy between self and others. Therefore, the current operating mechanism of LKM is relatively vague and needs to be further clarified in future research. This can provide a deeper understanding of the specific operating mechanism of LKM in mental health intervention, clarify the role of its sub-latitude in mental health intervention. It is possible to obtain practical, effective, and feasible methods for cultivating the mental toughness of the population and coping with psychological obstacles.

In addition, some studies have shown that the cost of face-to-face training of LKM is too high [2], There are huge financial barriers to hiring professional meditation teachers [30]. With the rapid progress and development of the current social Internet, online meditation training may become a practical and effective method to reduce costs. The establishment of related meditation website platforms may provide more effective and convenient help for the online training of LKM.

\section{REFERENCES}

[1] Bodhi B. Comprehensive Manual of Abhidhamma: The Abhidhammattha Sangaha[M]. Pariyatti Publishing, 2012.

[2] Peng Yanqin. Compassion and loving homes compassion Zen and mental and physical health [J].
Journal of Nanjing Normal University (SOCIAL SCIENCE EDITION), 2018 (03): 120-129

[3] Zeng X, Chan V Y L, Liu X, et al. The four immeasurables meditations: differential effects of appreciative joy and compassion meditations on emotions[J]. Mindfulness, 2017, 8(4): 949-959.

[4] Zeng X, Chiu C P K, Wang R, et al. The effect of loving-kindness meditation on positive emotions: a meta-analytic review[J]. Frontiers in psychology, 2015, 6: 1693.

[5] Gilbert P, Basran J, MacArthur M, et al. Differences in the semantics of prosocial words: an exploration of compassion and kindness[J]. Mindfulness, 2019, 10(11): 2259-2271.

[6] Salzberg S . Loving kindness the revolutionary art of happiness[J]. shambhala pubns, 2004.

[7] [7]Singer T, Klimecki O M. Empathy and compassion[J]. Current Biology, 2014, 24(18): R875-R878.

[8] Zeng X, Liu S, Liu X. Application of loving kindness meditation from the perspective of psychology [J]. Progress of psychological science, 2013,21 (08): 1466-1472.

[9] Hao J, Liu C, Feng S, et al. Imagination-Based Loving-Kindness and Compassion Meditation: A New Meditation Method Developed from Chinese Buddhism[J]. Journal of Religion and Health, 2021: 1-17.

[10] Hofmann S G, Grossman P, Hinton D E. Lovingkindness and compassion meditation: Potential for psychological interventions[J]. Clinical psychology review, 2011, 31(7): 1126-1132..

[11] Suzuki S. Zen mind, beginner's mind[M]. Shambhala Publications, 2020.

[12] Shonin E, Van Gordon W, Compare A, et al. Buddhist-derived loving-kindness and compassion meditation for the treatment of psychopathology: A systematic review[J]. Mindfulness, 2015, 6(5): 1161-1180.

[13] Galante J, Galante I, Bekkers M J, et al. Effect of kindness-based meditation on health and wellbeing: a systematic review and meta-analysis[J]. Journal of consulting and clinical psychology, 2014, 82(6): 1101

[14] He X, Shi W, Han X, et al. The interventional effects of loving-kindness meditation on positive emotions and interpersonal interactions[J]. Neuropsychiatric Disease and Treatment, 2015, 11: 1273. 
[15] Sirotina U, Shchebetenko S. Loving-kindness meditation and compassion meditation: do they affect emotions in a different way?[J]. Mindfulness, 2020, 11(11): 2519-2530.

[16] Ilies I A, Egan H, Mantzios M. Comparing state anxiety and mindfulness between mindfulness and loving-kindness meditation whilst controlling for the effect of altruism and boredom[J]. Current Issues in Personality Psychology, 2019, 7(2): 109119-109-119.

[17] Totzeck C, Teismann T, Hofmann S G, et al. Loving-kindness meditation promotes mental health in university students[J]. Mindfulness, 2020, 11(7): 1623-1631.

[18] Weibel D T, McClintock A S, Anderson T. Does loving-kindness meditation reduce anxiety? Results from a randomized controlled trial[ $\mathrm{J}]$. Mindfulness, 2017, 8(3): 565-571.

[19] Shahar B , Szsepsenwol O, Zilcha-Mano, Sigal, et al. A Wait-List Randomized Controlled Trial of Loving-Kindness Meditation Programme for SelfCriticism[J]. Clinical Psychology \& Psychotherapy, 2015.

[20] Kirby J N , Laczko D . A Randomized Micro-Trial of a Loving-Kindness Meditation for Young Adults Living at Home with their Parents[J]. Journal of Child and Family Studies, 2017, 26(7):1888-1899.

[21] Reb J, Junjie S, Narayanan J. Compassionate dictators? The effects of loving-kindness meditation on offers in a dictator game[C]/The Effects of Loving-Kindness Meditation on Offers in a Dictator Game. IACM 23rd Annual Conference Paper. 2010.

[22] Engel Y, Noordijk S, Spoelder A, et al. Selfcompassion when coping with venture obstacles: Loving-kindness meditation and entrepreneurial fear of failure[J]. Entrepreneurship Theory and Practice, 2021, 45(2): 263-290.

[23] Engert V, Kok B E, Papassotiriou I, et al. Specific reduction in cortisol stress reactivity after social but not attention-based mental training $[\mathrm{J}]$. Science Advances, 2017, 3(10): e1700495.

[24] Leppma M, Young M E. Loving - kindness meditation and empathy: A wellness group intervention for counseling students[J]. Journal of Counseling \& Development, 2016, 94(3): 297-305..

[25] Carson J W, Keefe F J, Lynch T R, et al. Lovingkindness meditation for chronic low back pain: Results from a pilot trial[J]. Journal of Holistic Nursing, 2005, 23(3): 287-304.
[26] Wren A A, Shelby R A, Soo M S, et al. Preliminary efficacy of a lovingkindness meditation intervention for patients undergoing biopsy and breast cancer surgery: A randomized controlled pilot study[J]. Supportive Care in Cancer, 2019, 27(9): 3583-3592.

[27] Lutz A, Brefczynski-Lewis J, Johnstone T, et al. Regulation of the neural circuitry of emotion by compassion meditation: effects of meditative expertise[J]. PloS one, 2008, 3(3): e1897.

[28] Shahar B, Szepsenwol O, Zilcha-Mano S, et al. A wait - list randomized controlled trial of loving kindness meditation programme for self criticism[J]. Clinical psychology \& psychotherapy, 2015, 22(4): 346-356.

[29] Fredrickson B L, Cohn M A, Coffey K A, et al. Open hearts build lives: positive emotions, induced through loving-kindness meditation, build consequential personal resources[J]. Journal of personality and social psychology, 2008, 95(5): 1045.

[30] Moadel-Robblee A, Camacho F, Milner G E, et al. Peer navigation-delivered loving kindness meditation: A pilot project[J]. Complementary Therapies in Medicine, 2021, 57: 102661.

[31] Luberto C M, Shinday N, Song R, et al. A systematic review and meta-analysis of the effects of meditation on empathy, compassion, and prosocial behaviors[J]. Mindfulness, 2018, 9(3): 708-724.

[32] Chen H, Liu C, Cao X, et al. Effects of LovingKindness Meditation on Doctors' Mindfulness, Empathy, and Communication Skills[J]. International Journal of Environmental Research and Public Health, 2021, 18(8): 4033.

[33] Bamber M D, Schneider J K. Mindfulness-based meditation to decrease stress and anxiety in college students: A narrative synthesis of the research[J]. Educational Research Review, 2016, 18: 1-32.

[34] Kirby J N, Laczko D. A randomized micro-trial of a loving-kindness meditation for young adults living at home with their parents[J]. Journal of Child and Family Studies, 2017, 26(7): 1888-1899.

[35] Trautwein F M, Naranjo J R, Schmidt S. Decentering the self? Reduced bias in self-vs. other-related processing in long-term practitioners of loving-kindness meditation[J]. Frontiers in psychology, 2016, 7. 